\title{
POLÍTICAS PÚBLICAS E MINISTÉRIO PÚBLICO, de Maria Tereza Uille Gomes ${ }^{1}$
}

\author{
Lucas Pereira da Silva ${ }^{2}$
}

- Enviado em 30/01/2016

- Aprovado em 24/02/2016

Para a tessitura da tese em pauta a referida autora teve como objetivo nuclear a releitura de temas transversais tais como Democracia, Direitos Humanos, Desenvolvimento, Planejamento e Políticas Públicas, para com base numa nova proposta de reformulação do processo de políticas públicas, compreender o papel do Ministério Público no controle externo dessas Políticas.

No que se refere a metodologia de trabalho a autora segue um delineamento com base na pesquisa de campo referenciada no Sistema de Informações dos e para Membros do Ministério Público (SIM-MP), e em pesquisa doutrinária e jurisprudencial, capaz de mostrar alguns exemplos do que o Ministério Público faz, bem como os conflitos e tensões que sua atuação pode gerar em relação a outros Poderes e Instituições, em especial, no combate ao "nepotismo". Para a coleta de dados a autora emprega além da pesquisa bibliográfica, o estudo documental e de casos. Trata-se de pesquisa aplicada porque gera conhecimentos úteis à solução de problemas sociais, e com conteúdo quantitativo e qualitativo.

Desde o primeiro capítulo intitulado: Democracia, direitos e políticas públicas, a autora constrói um trabalho bem fundamentado e busca situar o Ministério Público visto sob vários ângulos, desde sua estrutura e organização e focaliza o Estado do Paraná, até descobrir se e como o Ministério Público, no campo das políticas públicas, pode contribuir de forma emergencial e

\footnotetext{
${ }^{1}$ Tese de autoria de Maria Tereza Uille Gomes, defendida no Programa de Pós-Graduação em Sociologia da UFPR, na linha Sociedade e Estado, em 2011, sob orientação do Prof. Dr. Ricardo Costa de Oliveira. Versão completa disponível na Biblioteca Digital da UFPR - http://dspace.c3sl.ufpr.br/dspace/bitstream/handle/1884/28014/R\%20-\%20T\%20\%20MARIA\%20TEREZA\%20UILLE\%20GOMES.pdf?sequence=1.

${ }^{2}$ Graduado em Psicologia pela Universidade Federal de Alagoas, mestre em Educação e docente efetivo nesta mesma universidade. Doutorando em Ciências Sociais pela Universidade Federal de Campina Grande. Endereço eletrônico: lpsic@bol.com.br
} 
planejada para atingir os 8 Objetivos de Desenvolvimento do Milênio das Nações Unidas, em especial, o $7^{\circ} \mathrm{ODM}$, aquele cujas metas o Brasil não atingiu até 2015.

No primeiro capítulo a autora parte das concepções de Karl Mannheim e, em especial, da sua obra intitulada "Liberdade, Poder e Planificação Democrática", e da proposta ali contida para se criar uma nova Instituição e, assim, compreender como ele entende o futuro da democracia através do aperfeiçoamento do processo de planejamento, a fim de construir uma visão globalizante do Sistema Social. Aborda-se, ainda, os Desafios da Democracia na América Latina Hoje, em uma visão atual de Jessé de Souza. Em seguida a autora busca transportar os ensinamentos teóricos de Mannheim para a realidade brasileira, pesquisando qual é a produção cientifica no campo das políticas públicas do Brasil, para, então, relacioná-la com campos pouco explorados, e investigar como se dá o processo de planejamento da administração pública.

Ainda no primeiro capítulo Maria Tereza procura compreender, no contexto histórico e evolutivo, como os direitos humanos e as políticas públicas podem contribuir para a planificação democrática. Faz esse esforço teórico através de autores consagrados como T.H.Marshall, Reinhard Bendix e Norberto Bobbio, além de dialogar com autores nacionais, a exemplo de Marta Arretche, Sonia Draibe, Maria Paula Dallari Bucci e Gilberto Bercovici.

No Capítulo II intitulado: Desenvolvimento e Construção de Políticas Públicas Ao se constatar que as políticas públicas são vistas sob uma ótica setorial mas que demandam uma visão global, cuja visão só se dá a partir da concepção do desenvolvimento e do planejamento, a autora traz referencias teóricas que tratam do desenvolvimento, tais como Pinto Ferreira, Costa Pinto, Amartya Sen, Ignacy Sachs, Bernard Kliksberg, e do planejamento na seara da Gestão Pública, a exemplo de Matias Pereira. Pretende assim, chegar a um conceito de desenvolvimento que permita, compreender como se dá o planejamento governamental no âmbito do Poder Executivo e com a participação do corpo político, no que tange ao planejamento, formulação, implementação de políticas públicas e avaliação. Discute assim, como se dá a engrenagem do sistema social e quais são as políticas públicas e os planos nacionais e regionais de desenvolvimento. É com base nesta visão sistêmica que a autora busca compreender o papel do Ministério Público no campo do desenvolvimento e das políticas públicas, tensionando com os gestores públicos, visando contribuir para a efetivação dos oito objetivos de desenvolvimento do milênio - ODM.

Trilhando um percurso teoricamente consistente, no terceiro capítulo, apesar do longo título: "O Planejamento Democrático do Desenvolvimento se instrumentaliza em Planos, e, esses Planos são documentos que simbolizam o detalhamento da política pública, permitindo o seu controle com vistas à efetivação dos direitos humanos". É nesse capítulo que a autora faz um resgate histórico da função do planejamento na estrutura do Estado, mostrando que o planejamento 
do desenvolvimento se instrumentaliza em Planos. E, então, a autora apresenta a proposta de reformulação do processo de políticas públicas num ciclo composto de 7 (sete) etapas, com a inclusão expressa dos Planos, cujas etapas, constituem o Processo de Planejamento do Desenvolvimento e das Políticas Públicas.

Ainda no terceiro capítulo a autora traz detalhes de como se desenvolvem as 7 (sete) etapas que vão do Planejamento até a Execução das políticas públicas. São elas: 1. agenda política; 2. diagnóstico; 3. formulação da política pública; 4. estratégia e decisão política com vistas à garantir o desenvolvimento; 5 . detalhamento da decisão política em planos e indicação dos programas; 6 . inclusão dos programas previstos nos planos no Plano Plurianual - PPA; 7. gestão do Plano Plurianual (com implementação dos programas, controle e avaliação).

Em seguida traz um destaque especial para a $5^{\mathrm{a}}$ etapa, que é a do detalhamento da decisão política em PLANOS, por se entender que a transformação da vontade popular democrática em PLANOS é que irá garantir o desenvolvimento e a efetivação dos direitos humanos. Pois os planos integram o processo de planejamento e servirão como instrumentos, como verdadeiros títulos executivos, para que se possa exigir o cumprimento da política pública nos moldes em que foi concebida e deliberada democraticamente.

É nesse mesmo capítulo que a autora mostra como se efetivam os planejamentos, discutidos e construídos, democraticamente, a partir de Conferências, e demonstra esse processo através de alguns Planos, tais como o Plano Nacional de Saúde, o Plano Nacional de Educação, o Plano Nacional de Educação em Direitos Humanos, o Plano Nacional de Cultura, o Plano Nacional de Assistência Social, o Plano Diretor, o Plano Nacional de Habitação e o Plano de Saneamento Básico. Enfatiza assim, a necessidade de regulação pelo Poder Público e a ampliação do controle social.

No quarto capítulo, intitulado: "Ministério Público e o Controle Externo das Políticas Públicas", a autora reflete sobre a compreensão sistêmica da complexa rede de interatividade que envolve o desafio de planejar democraticamente a construção do ciclo das políticas públicas a fim de que os direitos humanos possam ser efetivados, passou-se a desvendar o papel de um dos novos atores no cenário das políticas públicas, que é o Ministério Público, a quem compete intervir para defender e promover a efetivação plena dos direitos humanos.

Dessa forma, o estudo realizado por Maria Tereza Uille Gomes assume uma importância teórico-prática como referência para as áreas de políticas públicas, planejamento e para as ciências sociais como um todo, por reunir elementos que fortalecem uma visão sistêmica e global das etapas do processo de planificação democrática no âmbito da administração pública, desde a formulação da política até a sua execução e avaliação, através de planos de ação e sistemas de informação e 
controle, para permitir à sociedade e a seus representantes legais uma melhor compreensão e reflexão acerca da ação dos governantes no planejamento, orçamento e gestão da coisa pública, com vistas à melhoria da qualidade de vida das pessoas. Nessas condições o estudo traz elementos atuais para uma leitura mais ampla das políticas públicas como uma arena de lutas, com interesses distintos a serem constantemente discutidos ao passo que a sociedade passa por transformações em seu cotidiano. 